\title{
QUALITY OF LIFE IN PATIENTS WITH ADOLESCENT IDIOPATHIC SCOLIOSIS
}

\author{
Aisel Oseku, \\ Surven Metolli ${ }^{2 i}$ \\ Sports University of Tirana, \\ Albania
}

\begin{abstract}
:
Idiopathic Adolescent Scoliosis (AIS) is a 3D spinal deformity that arises approximately during puberty. In some cases, the curvature of AIS continues to progress toward more severe over adulthood, which generally requires an invasive surgery reconstruction. To investigate quality and status of life (QOL) in patients with idiopathic adolescent scoliosis (AIS). Inclusion criteria were patients with non-surgical treatment for AIS with Cobb angle over or $10^{\circ}$, and age $\leq 23$ years old. A total of 45 patients with AIS were included and divided into three groups ( single main thoracic MT the curve group, $n=15$ ); (single thoracolumbar curve TL/L group, $\mathrm{n}=20$ ); (double major thoracic lumbar curve DM group, $n=10$ ), based on the location of the curve in skeletal maturity. Postero-anterior standing Formetric (Functional Analysis of the Musculoskeletal System), were evaluated at skeletal maturity. QOL was evaluated using the visual analogue scale (VAS) for back pain (BP) (maximum: $10 \mathrm{~cm}$ ), the SRS -22, and the Oswestry Disability Index Questionnaire (ODIQ). In all groups, severe scoliosis progressed by approximately 0.5 /for year from the time of skeletal maturity. The TL/L and DM groups showed a significantly worse visual analogue scale, scores for back pain compared to MT group $(p<0.05)$. The groups involved showed significantly worse results for the SRS-22 selfimaging domain. The TL/L group showed worse outcomes for walking ability and areas of social function of the Oswestry Disability Index Questionnaire for the assessment of back pain $(\mathrm{p}<0.005)$. AIS patients with single MT curve maintain equal QOL (Quality of life) status compared to the other groups. Patients with TL/L structural curves are likely to experience a greater annual curve progression due to substantial back pain or more specific back pain where the QOL status during the daily activity is deplorable.
\end{abstract}

Keywords: Adolescent Idiopathic Scoliosis, quality of life, health care, curve progression, disability

i Correspondence: email aoseku@ust.edu.al, smetolli@ust.edu.al 


\section{Introduction}

Scoliosis is defined as a lateral curvature of the spinal cord with Cob angle of $10^{\circ}$ or more. Scoliosis usually develops before puberty and leads to a 3-dimensional deformation of the trunk. Compared to healthy individuals, patients with idiopathic scoliosis have reduced overall and asymmetric balance of the transversus abdominal muscles. Therefore, treatment strategies should be defined in perspective to prevent curve progression, with curve correction and long-term maintenance, we must base on the natural history of the AIS curve.

In the case of non - operated AIS, curves that progress to $40-50^{\circ}$ at skeletal maturity tend to continue to progress throughout adulthood, most often at a rate of approximately $1^{o}$ per year, as assessed radiographically.

Concerning quality of life (QOL), several studies have reported complications, including back pain, shortness of breath, difficulty in physical activity, psychological distress, and body shape self-awareness in subsequent long-term surveys. Recently, various patient-assessed questionnaires have been widely used to assess QOL status in epidemiological or clinical research.

Danielsson et al. reported that 77 non-operated AIS patients, with a mean age of 32 years, had similar scores in the short form-36 (SF-36) and Scoliosis Research Society Outcome Instrument-22 (SRS-22) evaluations compared to the age-matched normal scales. Pesenti et al. reported 258 AIS patients (100 operated on in adolescence, 116 never operated on, and 42 operated on in adulthood), with a mean follow-up 27.8 years, who showed no significant differences in Oswestry Disability Index (ODI) and SRS-22 among the 3 groups. Therefore, the present study aimed is to investigate the quality and status of life (QOL) in patients with idiopathic adolescent scoliosis (AIS).

\section{Materials and Methods}

Inclusion criteria were patients with non-surgical treatment for AIS with Cobb angle over or $10^{\circ}$, and age $\leq 23$ years old. A total of 45 patients with AIS were included and divided into three groups (single main thoracic MT the curve group, $\mathrm{n}=15$ ); (single thoracolumbar curve TL/L group, $\mathrm{n}=20$ ); (double major thoracic lumbar curve DM group, $\mathrm{n}=10$ ), based on the location of the curve in skeletal maturity. Postero-anterior standing Formetric (Functional Analysis of the Musculoskeletal System), were evaluated at skeletal maturity. QOL was evaluated using the visual analogue scale (VAS) for back pain (BP) (maximum: $10 \mathrm{~cm}$ ), the SRS -22, and the Oswestry Disability Index Questionnaire (ODIQ).

Posteroanterior posture in Formetric (Functional Analysis of the Musculoskeletal System), was assessed for the skeletal maturity at the time of the study. Coronal parameters include the MT and TL / L Cobb angles. Sagittal parameters included the vertical sagittal axis (SVA), thoracic kyphosis (TK, T5-T12), thoracolumbar kyphosis (TLK, T10-L2), and lumbar lordosis (LL, L1-S1). For sagittal measurements with formetric, positive and negative values indicate kyphosis and lordosis, respectively. 
Group differences were evaluated using the Analysis of variance (ANOVA), and a P-value $<0.05$ was considered statistically significant.

\section{Results}

The MT curve is significantly increased by approximately $10^{\circ}$ from the time of skeletal maturity to the time of the survey ( all comparisons, $\mathrm{p}<005$ ), and there were no significant differences of the annual progress of the curve between the groups. TL/L curves also increased significantly, whereas the TL/L and DM groups showed a greater annual curve progression $(\mathrm{p}=0.0064)$.

In terms of sagittal parameters, there were no significant differences between the 3 groups at the time of the study. The QOL results are presented in Table 1. Back Pain (BP) scores for the VAS scale in the TL/L and DM groups were significantly higher compared to the MT group ( $\mathrm{p}<0.05)$. About SRS-22, self-imaging scores in all three scoliosis groups were significantly lower.

On the other hand, the ODI (Disability Index), there were no significant differences among the 3 groups.

Table 1: Disability Index

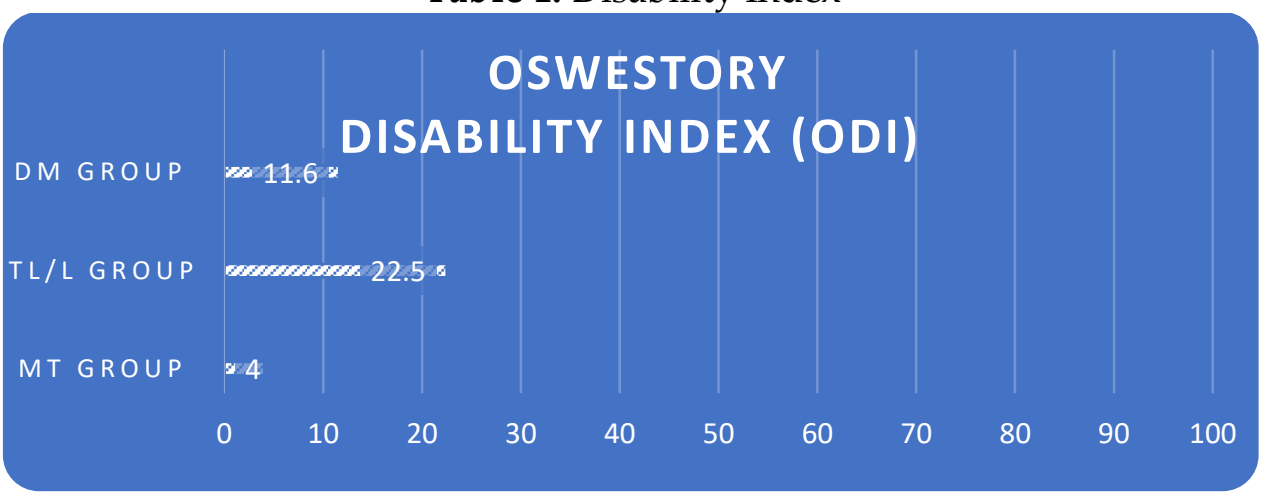

Source: Author's collection

\section{Conclusion}

AIS patients with single MT curve maintain equal QOL(Quality of life) status compared to the other groups. Patients with TL/L structural curves are likely to experience a greater annual curve progression due to substantial back pain or more specific back pain where the QOL status during the daily activity is deplorable.

Therefore, physicians should perform periodic evaluations of patients with AIS (Adolescents Idiopathic Scoliosis) with TL/L structural scoliosis during adulthood and giving informed consent about the future course of deformity by patients and their families.

\section{Conflict of Interest Statement}

The authors declare no conflicts of interests. 


\begin{abstract}
About the Authors
Aisel Oseku is a Lecturer/ Assistant Professor, Department of Biomedical and Humanities Disciplines, Faculty of Sciences and Rehabilitation, Sports University of Tirana. Bachelor Degree in Physiotherapy Science from the (University Our Lady of Good Counsel) Tirana, Albania. Current research interest the physical capabilities, body type, and activity level in order to prescribe exercise and other physical means to help improve function.

Surven Metolli is a Lecturer / Head of Health and Movement Department, Faculty of Physical Activity and Recreation, Sports University of Tirana. Received a Science Degree in General Medicine from the Faculty of Medicine, University of Tirana. Current research interest the physical rehabilitation after mechanical traumas.
\end{abstract}

\title{
References
}

Green BN, Johnson C, Moreau W. (2009). Is physical activity contraindicated for individuals with scoliosis? A systematic literature review. J Chiropr Med, 2009, 8: 25-37. [Medline] [CrossRef].

Weinstein SL, Zavala DC, Ponseti IV. Idiopathic scoliosis: long-term follow-up and prognosis in untreated patients. J Bone Joint Surg Am 1981;63:702-12.

Weinstein SL, Ponseti IV. Curve progression in idiopathic scoliosis. J Bone Joint Surg Am 1983;65:447-55.

Weinstein SL, Dolan LA, Spratt KF, et al. Health and function of patients with untreated idiopathic scoliosis: a 50-year natural history study. JAMA 2003;289:559-67.

Ascani E, Bartolozzi P, Logroscino CA, et al. Natural history of untreated idiopathic scoliosis after skeletal maturity. Spine 1986;11:784-9.

Pehrsson K, Danielsson A, Nachemson A. Pulmonary function in adolescent idiopathic scoliosis: a 25 year follow up after surgery or start of brace treatment. Thorax 2001;56:388-93.

Goldberg MS, Mayo NE, Poitras B, et al. The Ste-Justine Adolescent Idiopathic Scoliosis Cohort Study. Part II: Perception of health, self and body image, and participation in physical activities. Spine 1994;19:1562-72.

Mayo NE, Goldberg MS, Poitras B, et al. The Ste-Justine Adolescent Idiopathic Scoliosis Cohort Study. Part III: Back pain. Spine 1994;19:1573-81.

Danielson AJ, Hasserius R, Ohlin A, et al. Health-related quality of life in untreated versus brace-treated patients with adolescent idiopathic scoliosis: a long-term follow-up. Spine 2010;35:199-205.

Pesenti S, Jouve JL, Morin C, et al. Evolution of adolescent idiopathic scoliosis: results of a multicenter study at 20 years' follow-up. Orthop Traumatol Surg Res 2015;101:619-22. 

copy, distribute, transmit or adapt the article content, providing a proper, prominent and unambiguous attribution to the authors in a manner that makes clear that the materials are being reused under permission of a Creative Commons License. Views, opinions and conclusions expressed in this research article are views, opinions and conclusions of the author(s). Open Access Publishing Group and European Journal of Physical Education and Sport Science shall not be responsible or answerable for any loss, damage or liability caused in relation to/arising out of conflict of interests, copyright violations and inappropriate or inaccurate use of any kind content related or integrated on the research work. All the published works are meeting the Open Access Publishing requirements and can be freely accessed, shared, modified, distributed and used in educational, commercial and non-commercial purposes under a Creative Commons attribution 4.0 International License (CC BY 4.0). 